\title{
Cidadania, corpo e punição: expansão e violação de direitos civis de adolescentes internados na antiga Febem/SP*
}

Recebido: 18.02 .18 Aprovado: 06.05.19

Liana de Paula**

Resumo: Este artigo discute a garantia de direitos civis e a proteção contra agressões físicas para adolescentes em cumprimento de medida de internação. A relação entre direitos civis e proteção do corpo dos adolescentes é aqui entendida a partir do conceito de cidadania disjuntiva e da noção de corpo incircunscrito, que remetem aos processos contraditórios de constituição da cidadania no Brasil. Com base em pesquisa qualitativa realizada em prontuários e pastas de adolescentes que deram entrada na antiga Febem de São Paulo, entre 1990 e 2006, e focando o que esses documentos permitem dizer sobre a violência física nas unidades de internação, o artigo apresenta como essa violência revela um paradoxo entre expansão e violação de direitos civis, tornando possível que investimentos na garantia desses direitos ocorram ao mesmo tempo em que sua violação permaneça na forma de castigos físicos.

Palavras-chave: Cidadania. Direitos civis. Agressões físicas. Adolescentes em conflito com a lei. Medida de internação.

\section{Citizenship, body, and punishment: expansion and violation of the civil rights of young offenders in custodial sentences at Febem/SP}

\begin{abstract}
This article analyses the guarantee of civil rights and the prevention against physical abuse for young offenders during custodial sentences. The analytical framework of this discussion considers the guarantee of rights for these young persons as an issue of citizenship, which constitution in Brazil is characterized by contradictory processes that are here defined in the concept of disjunctive citizenship and in the notion of unbounded body. The data presented in this article refers to a qualitative research in the dossiers of young offenders who had been sentenced to incarceration in one of the juvenile detention centers of Febem/São Paulo, from 1990 until 2006. And the results demonstrate how the situations of physical violence registered in the dossiers (including unofficial corporal punishments)reveal important changes and permanencies that can be understood as part of the contradictory processes of violation and expansion of the civil rights of young offenders.
\end{abstract}

Key words: Citizenship. Civil rights. Physical abuse. Young offenders. Custodial sentence.

\author{
* Este artigo \\ apresenta resultados \\ de pesquisa que \\ realizei entre \\ 2013 e 2016, com \\ financiamento do \\ Conselho Nacional \\ de Desenvolvimento \\ Científico e \\ Tecnológico (CNPq). \\ Uma análise parcial \\ destes dados foi \\ apresentada em \\ 2015, no formato \\ de paper, no XVII \\ Congresso Brasileiro \\ de Sociologia, em \\ Porto Alegre, e no \\ XXXIX Encontro \\ Anual da Anpocs, em \\ Caxambu. Agradeço \\ a colaboração \\ de Laís Silva \\ Vieira, bolsista de \\ iniciação científica \\ da pesquisa, na \\ preparação destes \\ dados. \\ ** Liana de Paula \\ é professora de \\ sociologia do \\ Departamento de \\ Ciências Sociais \\ da Universidade \\ Federal de São \\ Paulo (Unifesp), \\ coordenadora \\ do Grupo de \\ Pesquisa sobre \\ Cidadania, Violência \\ e Administração \\ da Justiça - \\ CiVAJ/Unifesp e
}


pesquisadora do Grupo de Pesquisa sobre Violência e Administração de Conflitos - Gevac/ UFSCar, que integra o Instituto de Estudos Comparados em Administração Institucional de Conflitos - INCT/ InEAC, Guarulhos, São Paulo, Brasil. Orcid: 0000-00020755-1468.

<liana.paula@ unifesp.br>.

\section{A promulgação} do ECA também esteve relacionada a um contexto internacional específico, marcado pelo surgimento de diversas normas das Nações Unidas para os direitos da infância e juventude, nos anos 1980.

2. O termo "justiça juvenil" é aqui utilizado em referência ao ramo específico dos poderes Judiciário e Executivo que atua na responsabilização de adolescentes que cometeram atos infracionais. Atualmente, a idade mínima para essa responsabilização no Brasil é de 12 anos, e a máxima é de 17 anos. A partir de 18 anos, o infrator é tratado como adulto e direcionado à Justiça Criminal.

\section{O recorte} temporal e a escolha dos casos para análise qualitativa foram efetivados em pesquisa anterior, realizada entre

\section{Introdução}

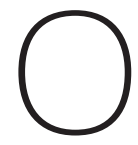
Estatuto da Criança e do Adolescente (ECA) é considerado um marco na legislação brasileira. Sua promulgação, em 1990, foi resultado do processo de redemocratização do país, nos anos 1980 , e da ação de movimentos sociais que, mobilizados desde meados dos anos 1970, defendiam o acesso de crianças e adolescentes a direitos como forma de enfrentar a até então chamada "questão do menor"(Paula, 2015) ${ }^{1}$. Com o ECA, que regulamenta o artigo 227 da Constituição Federal, esses movimentos sociais buscaram garantir o alinhamento da legislação da infância e adolescência com a agenda democrática de promoção da cidadania e a garantia de direitos.

No que se refere especificamente aos adolescentes que cometeram atos infracionais - e que podem ser equiparados a crimes na legislação penal -, o ECA os define como sujeitos de direitos, além de prever uma série de mudanças no funcionamento da justiça juvenil². Entre essas mudanças, estão a previsão do devido processo legal; a previsão de um conjunto de medidas socioeducativas a serem aplicadas conforme a gravidade do ato infracional cometido; a limitação da privação de liberdade a casos excepcionais e respeitando o princípio de brevidade; e a garantia dos direitos que não tenham sido restringidos pela medida aplicada.

Neste artigo, proponho a discussão sobre essas mudanças legais, a visarem a constituição dos adolescentes autores de ato infracional como sujeitos de direitos, que promoveram rupturas nas práticas da medida socioeducativa de internação, tornando possível o acesso dos adolescentes privados de liberdade a direitos de cidadania. Para tanto, parto da construção da garantia de direitos desses adolescentes como uma questão de cidadania, o que remete aos processos contraditórios a partir dos quais os direitos de cidadania têm se constituído no Brasil e que são compreendidos por Teresa Caldeira (2000) e James Holston (2013) com fundamento no conceito de cidadania disjuntiva.

A partir desses processos, foco a discussão sobre os direitos civis e sua relação com a noção de corpo incircunscrito, desenvolvida por Caldeira (2000), para apresentar parte dos resultados da pesquisa qualitativa realizada em prontuários e pastas de adolescentes que deram entrada nas unidades de internação da antiga Fundação Estadual do Bem-Estar do Menor de São Paulo (Febem/SP) entre os anos 1990 e $2006^{3}$. Esses resultados referem-se à questão da violência física nas unidades de internação e como essa revela um paradoxo entre a expansão dos direitos civis dos adolescentes e a permanência de sua violação no emprego de 
castigos físicos, reiterando a importância da noção de corpo incircunscrito como aspecto-chave da cidadania disjuntiva no Brasil.

\section{Cidadania, tutela \\ e garantia de direitos}

Uma das principais rupturas entre o ECA e a legislação anterior é a constituição formal de crianças e adolescentes como sujeitos de direitos, garantindo-lhes juridicamente o direito a ter direitos. A ruptura dá-se, portanto, no sentido da universalização dos direitos de cidadania, passando a incluir crianças e adolescentes no status de cidadãos (Paula, 2015). Contudo, essa universalização traz consigo novas tensões, que são, em parte, características da própria constituição da cidadania no Brasil e, em parte, específicas da questão da infância e adolescência.

No início do século XX, quando a justiça juvenil foi criada no país como Justiça de Menores, o público a quem se destinava eram as crianças e os adolescentes pobres que circulavam pelas ruas das cidades. No Rio de Janeiro e em São Paulo, industriais, juristas e autoridades da época defendiam a retirada dessas crianças e desses adolescentes das ruas, evitando o que acreditavam ser o perigo moral que as ruas representavam (Gregori, 2000). Em um primeiro momento, não havia consenso se a solução seria inseri-los diretamente no mundo de trabalho, como aprendizes, ou se deveriam ser encaminhados a instituições de assistência e reforma para serem preparados para essa inserção (Alvarez, 2003; Santos, 1999).

Com a promulgação do primeiro Código de Menores, em 1927, estabeleceu-se a internação em instituições de assistência e reforma como a principal resposta do Estado para lidar com crianças e adolescentes pobres que fossem considerados abandonados, carentes ou infratores pela então criada Justiça de Menores, conferindo-Ihe, assim, um caráter assistencial. Contudo, como observa Marcos César Alvarez (2003), esse caráter assistencial não significou uma ampliação de direitos para a população pobre urbana, mas definiu um tratamento penal especial para os que fossem considerados potencialmente perigosos.

Muito mais, portanto, que uma lei que garantisse direitos à população pobre, o Código reuniu principalmente um conjunto de dispositivos legais a partir dos quais o Estado poderia tutelar as crianças e os adolescentes "anormais", que potencialmente poderiam se tornar criminosos, ao garantir, em contrapartida, procedimentos penais especiais, mais adequados a evitar a impunidade e obter a necessária recuperação moral desses indivíduos.
2008 e 2010 sob a coordenação de Marcos César Alvarez, com financiamento do CNPq. Esse recorte abrange prontuários e pastas com data de início entre 1990, ano de promulgação do ECA, e 2006, ano em que a denominação da Febem/SP foi substituída por Fundação Casa/SP. Os 32 casos para análise qualitativa (aproximadamente dois casos para cada ano do recorte temporal) foram selecionados a partir da coleta de dados de amostra quantitativa (de 1.581 casos). 
O Código de Menores se constituiu, portanto, muito mais como um instrumento de defesa social do que como um instrumento de ampliação da cidadania (Alvarez, 2003: 211-212).

Ao visarem a tutela de crianças e adolescentes pobres considerados abandonados, carentes ou infratores - e, portanto, potencialmente perigosos -, o Código de Menores e seus procedimentos penais especiais engendraram o processo de menorização dessas crianças e desses adolescentes, circunscrevendo-os à categoria menor (ver, principalmente, Alvarez, 1989; também, Alvim \& Valladares, 1988). Além disso, ao operar no registro da tutela, o Código de Menores excluía-os do registro de cidadania, de modo que seu acesso a serviços de assistência social não poderia ser entendido como um direito.

A legislação brasileira, a partir dos anos 1930, manteve as tendências presentes no Código de Menores (Alvarez, 2003), excluindo o acesso de crianças e adolescentes pobres ao registro de cidadania, uma vez que esse acesso passou a depender exclusivamente da carteira de trabalho assinada.

Para Wanderley Guilherme dos Santos (1994), o conceito de cidadania regulada é central para compreender a legislação desse período, bem como a política econômica e social entre os anos 1930 e 1980, uma vez que esse conceito permite compreender como se operavam as desigualdades entre os incluídos e os excluídos no registro da cidadania. Nesse sentido, Santos chama atenção para o fato de que a cidadania regulada implicava um status de cidadania que não era universal, mas dependente do status ocupacional. Assim, a carteira de trabalho assinada era o documento que regulava o acesso aos direitos de cidadania.

Se a cidadania era definida pelo status ocupacional, crianças e adolescentes estavam fora desse registro, uma vez que a legislação produzida a partir dos anos 1920 e 1930 tendia a restringir o uso de sua força de trabalho. Para crianças e adolescentes pobres, o registro que se colocava então era o da tutela estatal, definida nos Códigos de Menores de 1927 e 1979 e exercida por meio da Justiça de Menores e dos serviços e instituições especializados de assistência social (Alvarez, 1989; 2003; Paula, 2017).

Estar no registro da tutela estatal significava, portanto, estar fora da cidadania, isto é, inseriam-se no registro da tutela aqueles a quem não se aplicava o status de cidadão. A tutela significava também que os que estavam fora desse status tornavam-se objeto da intervenção do Estado. Assim, as crianças e os adolescentes pobres que fossem considerados pela Justiça de Menores como abandonados, ca- 
rentes ou infratores não eram vistos como cidadãos perante o Estado, mas como objetos de sua tutela.

Com a promulgação da Constituição Federal de 1988 e do ECA, em 1990, a cidadania deixa de ser regulada pela ocupação de posto formal no mercado de trabalho e ganha status universal conferido a todos os nascidos no país, o que significa a inclusão, ao menos formal, de crianças e adolescentes no registro da cidadania. Assim, passaram eles a ser reconhecidos legalmente como cidadãos perante o Estado, e não mais como objeto de sua tutela. Por isso, e diferentemente dos Códigos de Menores, o ECA pode ser considerado instrumento formal de ampliação da cidadania.

Contudo, como aponta James Holston (2013), a universalização do status da cidadania não implica, necessariamente, a anulação de operações de produção de desigualdades no seu acesso. Nesse sentido, Holston observa que a cidadania no Brasil é caracterizada por ser, ao mesmo tempo, universalmente incluível na afiliação e fortemente desigual em sua distribuição. Mesmo após a Constituição de 1988, o acesso à cidadania permanece desigualmente distribuído entre a população nacional, levando à "coincidência da política democrática com a violência disseminada e a injustiça contra os cidadãos" (Holston, 2013: 397).

Para compreender a distribuição desigual do acesso à cidadania, Holston trabalha com a perspectiva de cidadania disjuntiva, segundo a qual:

[...] os processos e as práticas que definem a cidadania são inerentemente disjuntivos - não cumulativos, lineares ou distribuídos de maneira homogênea entre os cidadãos, mas sempre uma mistura de elementos progressivos e regressivos, desequilibrados, heterogêneos e corrosivos (Holston, 2013: 398).

Também a trabalhar nessa perspectiva, Teresa Caldeira (2000) defende que a cidadania brasileira pode ser considerada disjuntiva porque, embora os direitos sociais - e políticos - sejam razoavelmente legitimados, os aspectos civis da cidadania não o são, são mesmo continuamente violados.

Ao retomar a definição de Thomas H. Marshall (1967) em seu ensaio sobre a evolução da cidadania na Inglaterra, entendemos como aspectos civis da cidadania aqueles que se referem à liberdade individual, ao direito de ir e vir, aos direitos de imprensa, pensamento e fé, ao direito de propriedade e de concluir contratos válidos e ao direito à Justiça. Segundo Marshall, o direito à Justiça difere dos demais porque é o direito do devido processo legal e de defender e afirmar todos 
os demais direitos em termos de igualdade. Por isso, as instituições mais relacionadas com os direitos civis são os tribunais de justiça. Os direitos políticos, por sua vez, englobam o direito de participar do exercício do poder político, seja como autoridade política seja como eleitor, sendo as instituições correspondentes o Parlamento e os conselhos de governo. Os direitos sociais, enfim, são mais abrangentes, a começar pelo direito de mínimo bem-estar econômico e segurança ao direito de participar, por completo, da herança social e de condução da vida de acordo com os padrões civilizatórios da sociedade. As instituições mais ligadas a esses direitos são o sistema educacional e os serviços sociais.

Para Marshall (1967), esses três tipos de direitos de cidadania evoluíram historicamente, sendo os direitos civis os primeiros a se desenvolverem na Inglaterra, no século XVIII, seguidos pelos direitos políticos, no século XIX, e pelos direitos sociais, no século XX.

Contudo, como aponta Santos (1994) - e reitera José Murilo de Carvalho (2004) -, a experiência de outros países indica que não é possível defender a universalidade dessa ordem de evolução histórica dos direitos de cidadania, tal como proposta por Marshall. Segundo os autores, no caso brasileiro, os direitos sociais desenvolveram-se antes dos direitos civis e políticos, além de ter havido momentos em que uns eram suspensos, enquanto outros expandiam-se.

Holston (2013) e Caldeira (2000) também se contrapõem à noção de evolução universal dos direitos de cidadania ao trabalharem com a perspectiva de cidadania disjuntiva. Para Caldeira, a cidadania no Brasil caracteriza-se como disjuntiva por ser marcada por processos contraditórios de simultânea expansão e desrespeito aos direitos de cidadania. Mais especificamente, o caso brasileiro é marcado pela disjunção porque os aspectos civis da cidadania são continuamente violados, apesar da expansão dos direitos políticos e sociais. E uma das principais dimensões dessa disjunção é a relação entre violação de direitos civis e violência, como será tratado a seguir.

\section{Cidadania, corpo e direitos civis}

Segundo Caldeira (2000), embora as violações de direitos humanos sejam comuns no mundo contemporâneo, o que é único no caso brasileiro é a associação dos direitos humanos a "privilégios de bandidos" e não a direitos universais. Para compreender essa associação, Caldeira observa como, na transição democrática dos anos 1980, o tema dos direitos humanos aparece relacionado aos direitos dos presos comuns e ao crescimento da violência urbana. 
Mais especificamente, a autora analisa a oposição aos defensores de direitos humanos e à campanha pela introdução da pena de morte - ambas nos anos 1980 - e pontua que o tema central nesses dois debates é o limite - ou sua inexistência - para a intervenção no corpo do criminoso. Ao focar o caso de São Paulo e do governo de Franco Montoro (1983-1987), Caldeira (2000) descreve tanto as dificuldades dos defensores de direitos humanos em fixarem a noção da universalidade desses direitos a partir da defesa dos direitos dos presos, quanto o sucesso da oposição a eles em associá-los a privilégios de criminosos. Para os opositores da expansão dos direitos humanos aos criminosos, a pena de morte seria uma resposta mais adequada ao crime e à natureza cruel do criminoso.

Nas entrevistas com moradores de São Paulo, realizadas entre os anos 1980 e 1990, Caldeira observa a forte adesão dos entrevistados a essa associação entre direitos humanos e privilégios de criminosos, além da aceitação e do apoio a formas dolorosas de punição ao crime. A pena de morte não era percebida, pelos entrevistados, como uma pena cruel, degradante ou desumana, além de estar menos associada ao processamento pelo sistema judiciário e mais à possibilidade de execução sumária dos criminosos pela polícia.

Nesse sentido, as falas dos entrevistados revelaram a tensão entre duas visões da punição, sendo a primeira relacionada à lei, à justiça e ao sistema judiciário; a segunda à vingança, ao corpo e à dor como instrumento de punição. A aceitação das formas dolorosas de punição, que aparece nessas falas, vincula-se à segunda visão, isto é, ao

[...] universo da vingança privada, imediata e sempre bastante física. Esse universo revela uma concepção específica de corpo e especialmente de inflição de dor como um meio de desenvolvimento moral e social (Caldeira, 2000: 360).

Nesse universo, a dor e as intervenções no corpo são meios de criar a ordem.

Caldeira chama atenção para a naturalidade com que se aceita, no Brasil, a punição física, defendendo-se o caráter pedagógico da dor, especialmente para aqueles que são considerados como não racionais (as crianças, os adolescentes, as mulheres, os pobres e os criminosos). Contra essas pessoas, que não compreenderiam outra linguagem, a violência seria necessária, pois seria uma linguagem que qualquer ser pode entender. A dor, portanto, seria um instrumento usado pela autoridade para corrigir o caráter, melhorar o comportamento ou produzir a submissão nos corpos dos dominados. 
Para Caldeira, a centralidade do corpo e a aceitação do uso da dor e da violência como formas de punição são manifestações de uma concepção específica de corpo, o corpo incircunscrito. Este, por sua vez, está associado à violência e à deslegitimação dos direitos civis no Brasil. O corpo do criminoso, sendo incircunscrito, é um corpo manipulável e aberto a intervenções e a castigos dolorosos.

[...] o que todas as intervenções relevam é uma noção de corpo incircunscrito. Por um lado, o corpo incircunscrito não tem barreiras claras de separação ou evitação; é um corpo permeável, aberto à intervenção, no qual as manipulações de outros não são consideradas problemáticas. Por outro lado, o corpo incircunscrito é desprotegido por direitos individuais e, na verdade, resulta historicamente de sua ausência. No Brasil, onde o sistema judiciário é publicamente desacreditado, o corpo (e a pessoa) em geral não é protegido por um conjunto de direitos que o circunscreveriam, no sentido de estabelecer barreiras e limites à intervenção ou abuso de outros (Caldeira, 2000: 370).

A concepção de corpo incircunscrito e sua relação com a deslegitimação dos direitos civis são um ponto fundamental para se observar as contradições entre expansão e desrespeito aos direitos de cidadania no Brasil. E é nesse sentido que Caldeira afirma que a compreensão dos aspectos disjuntivos de nossa cidadania passa por essa associação entre corpo incircunscrito, violência e violação dos direitos civis.

Ao adotar a perspectiva de Caldeira (2000) da cidadania disjuntiva e da concepção de corpo incircunscrito como produtora da disjunção dos direitos de cidadania no Brasil, no sentido de deslegitimar os direitos civis em relação aos demais, tenho buscado identificar se e como as práticas das medidas socioeducativas estão relacionadas à expansão ou ao desrespeito dos direitos civis e sociais de adolescentes em conflito com a lei. Enquanto os direitos sociais dos adolescentes podem ser entendidos, empiricamente, como o acesso à educação, à saúde e à assistência social, os direitos civis estão relacionados ao acesso à justiça e à circunscrição do corpo, vedando intervenções e punições físicas. São, portanto, duas principais linhas de análise que buscam identificar as possíveis contradições entre expansão e desrespeito aos direitos de cidadania e, com isso, avaliar em que medida a proposta de garantia de direitos do ECA tem promovido ou não rupturas nas práticas destinadas a esses adolescentes. Apresento, a seguir, parte dos resultados da pesquisa que desenvolvi nos arquivos da antiga Febem/SP e que são relativos à primeira linha de análise, focada nas relações entre direitos civis, corpo e violência especificamente na medida socioeducativa de internação. 
Como a violência física aparece nos registros institucionais da antiga Febem/SP? Pode-se dizer que há regularidades nas formas como esse tipo de violência é registrada nos documentos $?^{4} \mathrm{E}$ o que esses registros permitem dizer sobre possíveis mudanças a partir da promulgação do ECA, no sentido de maior circunscrição dos corpos dos adolescentes e, portanto, de expansão de seus direitos civis?

Para responder a essas questões, analisei uma amostra qualitativa de 32 casos de adolescentes que deram entrada em unidades de internação da antiga Febem/SP entre os anos 1990 e 2006. Essa amostra havia sido selecionada em uma pesquisa anterior, de caráter exploratório, coordenada por Marcos César Alvarez e financiada pelo CNPq (Alvarez et alii, 2009) 5 .

Duas observações metodológicas em relação à amostra qualitativa são necessárias. A primeira se refere ao recorte temporal usado. O primeiro ano incluído na amostra é o da própria promulgação do ECA, portanto as mudanças que analisarei neste artigo se referem ao processo de implantação da lei, que tem sido marcado por resistências, disputas políticas e lentidão ${ }^{6}$. Já o ano final do recorte temporal foi escolhido por ser último ano de existência da Febem/SP com essa nomenclatura. Em dezembro de 2006, a nomenclatura foi alterada para Fundação Centro de Atendimento Socioeducativo ao Adolescente (Casa), simbolizando a adequação do órgão estadual ao léxico do ECA pela substituição dos termos "bem-estar" e "menor" pelos termos "atendimento socioeducativo" e "adolescente".

A segunda observação metodológica diz respeito à fonte dos dados: os prontuários e as pastas dos adolescentes são conjuntos documentais produzidos ao longo de sua permanência nas unidades de internação e contam sua vida institucional. Quando o adolescente ingressava pela primeira vez na Febem/SP, era aberto um prontuário, que permanecia no Núcleo de Documentação do Adolescente (NDA), e uma pasta, que seguia com ele para a unidade onde fosse internado. Prontuário e pasta recebiam a mesma numeração, que os vinculava àquele adolescente, e eram localizados e alimentados com novos documentos toda vez que ele voltasse à Febem/SP. Uma vez que era o adolescente que recebia um único número de identificação institucional, foi possível estabelecer que ele fosse a unidade de análise, apesar da existência de dois conjuntos documentais - prontuário e pasta.

Conforme constatado em pesquisas anteriores (Alvarez et alii, 2009; Hernandes, 2005), os prontuários compilam cópias e originais de documentos referentes à
4. A análise dos dados privilegiou os registros de violência física nas unidades de internação, embora seja possível também identificar a ocorrência de violência simbólica. Sobre as definições de violência física e simbólica, ver Porto (2010).

5. Durante a coleta dos dados da amostra quantitativa, os pesquisadores foram orientados a registrar em um caderno de pesquisa os casos que haviam chamado sua atenção e justificar o interesse. Desses, indicaram 32 para análise qualitativa, a partir da orientação de distribuir a seleção cobrindo os 16 anos do recorte temporal da pesquisa (portanto, dois casos para cada ano). Entre as justificativas para a escolha dos casos para análise qualitativa, estão históricos familiares dos adolescentes, questões de saúde dos adolescentes e conflitos entre a equipe da Febem e o Poder Judiciário.

6. A lentidão pode ser exemplificada no período de 22 anos que separa o ECA e a promulgação da lei que cria o Sistema Nacional de Atendimento Socioeducativo (Sinase) e regulamenta a execução das medidas 
socioeducativas (Lei Federal 12.594/2012).

7. Cabe lembrar que a pesquisa enfocou os registros de violência física quando esta ocorreu dentro das unidades de internação da Febem. Registros de violência física ocorrida em delegacias e cadeias públicas, embora existentes nos casos analisados, não foram considerados. comunicação institucional entre a Febem/SP e, principalmente, o Poder Judiciário, constituindo um registro da prestação de contas sobre o período em que o adolescente esteve sob custódia. Nos prontuários, eram juntados documentos como cópia do boletim de ocorrência do ato infracional cometido pelo adolescente, cópias de partes do processo judicial (em especial, a sentença determinando a internação), dados sobre o adolescente coletados na Febem/SP, ofícios trocados entre essa instituição e o Poder Judiciário, guia de transferência do adolescente para outra unidade de atendimento (internação provisória, internação ou semiliberdade), relatórios técnicos de acompanhamento do caso, termo de entrega do adolescente aos pais ou responsável (quando desinternado), entre outros.

Já as pastas, além de espelharem a documentação dos prontuários, contêm outros registros originais, referentes às atividades realizadas no interior das unidades da Febem/SP, tais como os atendimentos feitos pelos técnicos (assistentes sociais e psicólogos). Nas pastas, portanto, há o registro mais minucioso do cotidiano institucional, com cartas, anotações, manuscritos e outros documentos cujas informações ora serviam de base para a produção de relatórios e ofícios encaminhados ao Poder Judiciário, ora eram omitidas dessa comunicação institucional. Assim, a documentação específica das pastas é importante fonte para o conhecimento das práticas realizadas durante a internação.

Ao buscar identificar as formas como a violência física aparece nos prontuários e nas pastas dos adolescentes, é preciso considerar que a violência registrada nesses conjuntos documentais é somente aquela que a Febem/SP permitia registrar, a partir de um conjunto de regras formais e tácitas. Ou seja, havia regras formais e tácitas que estabeleciam o que poderia ou não ser registrado e como poderia ser registrado, e isso incluía as ocorrências de violência física nas unidades de internação.

Nesse sentido, ao adotar a perspectiva de Michel Foucault (2002) de olhar as limitações das práticas discursivas como positividades, isto é, como regras que estabelecem o conjunto de objetos, enunciações e conceitos sobre os quais se pode falar, é possível identificar nos prontuários e pastas dos adolescentes internados algumas regularidades sobre o que a Febem/SP se permitia dizer a respeito da violência física em suas unidades.

Dos 32 casos analisados, foram encontrados registros de violência física nas unidades de internação em $18^{7}$, e esses registros apareceram em diferentes tipos de documentos. Nos prontuários, os registros foram encontrados em ofícios, boletins 
de ocorrência, pedidos de exame de corpo de delito e relatórios técnicos, que informavam o Poder Judiciário sobre o desenvolvimento da medida socioeducativa de internação. Nas pastas, além do espelhamento dos documentos dos prontuários, há os registros de atendimento de psicólogos e assistentes sociais que relatam queixas dos adolescentes vítimas ou orientações dadas a adolescentes agressores. Também podem ser encontrados registros de ferimentos e queixas realizados pelos adolescentes nas chamadas pastas de saúde ou pastas médicas, que se encontram apensadas às pastas.

Os tipos de documentos e o volume de informação encontrados nos casos analisados variou de acordo com os autores da violência física, havendo diferenças substantivas nos registros que se referem aos próprios adolescentes internados enquanto perpetradores de violência física dentro das unidades de internação e nos registros que se referem à violência física causada pelos funcionários da antiga Febem/SP.

A violência perpetrada pelos adolescentes internados teve como vítimas tanto os funcionários como outros adolescentes e os resultados desta pesquisa indicam que os prontuários e as pastas são importantes fontes no registro desse tipo de violência. Dos 18 casos em que há registros de violência física dentro das unidades de internação, em 17 adolescentes foram apontados como agressores (todos os casos do Quadro 1 abaixo, exceto o caso 2 ), em situações muitas vezes traduzidas na linguagem institucional como ocorrências disciplinares ${ }^{8}$. Em 15 desses casos, os adolescentes a quem os prontuários e as pastas pertenciam foram apontados como autores de agressão física, sendo outros adolescentes as vítimas em $11 \mathrm{ca}$ sos (casos 1 e 5 a 14), funcionários as vítimas em um caso (caso 16), e tanto adolescentes quanto funcionários as vítimas em três casos (casos 4, 15 e 18). Dentre os apontados com autores de violência física, sete deles também foram vítimas de agressão por parte de outros adolescentes e/ou de funcionários (casos 4, 6, 8, 11 , 13, 14 e 18). Em apenas dois dos 17 casos os adolescentes a quem os prontuários e as pastas pertenciam foram indicados somente vítimas de violência física, e em ambos os casos a agressão foi perpetrada por outros adolescentes internados (casos 3 e 17).

O volume e a variedade dos tipos de documentos produzidos para registrar a violência física entre adolescentes são relativamente extensos, se comparados aos que relatam a violência física perpetrada pelos funcionários, e envolvem o encaminhamento de ofícios, relatórios técnicos, cópias de boletins de ocorrência e documentos de saúde (exames e laudos) ao Poder Judiciário, como pode ser observado nos prontuários. Nas pastas dos adolescentes, também há maior deta-
8. São ocorrências disciplinares a agressão a outros internados e aos funcionários, o envolvimento em tumulto e rebelião, e a fuga. Os casos de fuga foram desconsiderados para a análise da violência perpetrada por adolescentes. 


\section{QUADRO 1}

CASOS DE ADOLESCENTES INTERNADOS NA ANTIGA FEBEM/SP,

ENTRE 1990 E 2006, EM QUE HÁ REGISTROS DE AGRESSÃO FÍSICA

\begin{tabular}{|c|c|c|c|c|c|}
\hline \multirow[b]{2}{*}{ Caso } & \multirow[b]{2}{*}{$\begin{array}{l}\text { Ano de início do } \\
\text { Prontuário e da Pasta }\end{array}$} & \multicolumn{2}{|c|}{ Apontado como autor de agressão } & \multicolumn{2}{|c|}{ Apontado como vítima de agressão } \\
\hline & & $\begin{array}{l}\text { Contra outro(s) } \\
\text { adolescente(s) }\end{array}$ & $\begin{array}{l}\text { Contra } \\
\text { funcionário(s) }\end{array}$ & $\begin{array}{l}\text { Agressor(es): } \\
\text { outro(s) } \\
\text { adolescente(s) }\end{array}$ & $\begin{array}{l}\text { Agressor(es): } \\
\text { funcionário(s) }\end{array}$ \\
\hline 1 & 1993 & Sim & & & \\
\hline 2 & 1994 & & & & Sim \\
\hline 3 & 1996 & & & Sim & \\
\hline 4 & 1997 & Sim & Sim & Sim & Sim \\
\hline 5 & 1997 & Sim & & & \\
\hline 6 & 1998 & Sim & & Sim & Sim \\
\hline 7 & 1998 & Sim & & & \\
\hline 8 & 1999 & Sim & & Sim & Sim \\
\hline 9 & 1999 & Sim & & & \\
\hline 10 & 2000 & Sim & & & \\
\hline 11 & 2001 & Sim & & Sim & \\
\hline 12 & 2001 & Sim & & & \\
\hline 13 & 2002 & Sim & & Sim & Sim \\
\hline 14 & 2002 & Sim & & Sim & Sim \\
\hline 15 & 2003 & Sim & Sim* & & \\
\hline 16 & 2005 & & $\mathrm{Sim}^{*}$ & & \\
\hline 17 & 2006 & & & Sim & \\
\hline 18 & 2006 & Sim* & Sim & & $\mathrm{Sim}$ \\
\hline
\end{tabular}

* A autoria da agressão não foi confirmada ou negada posteriormente pela própria equipe de funcionários.

Fonte: Pesquisa Práticas socioeducativas e garantia de direitos: a (des)constituição do sujeito de direitos a partir da internação de adolescentes em conflito com a lei, 2016.

9. Nos casos analisados, não foi encontrado nenhum registro de denúncias de violência física que tivessem sido remetidas à Corregedoria da Febem/SP.

Ihamento desse tipo de violência nos registros de atendimento técnico e médico, além da repetição dos documentos dos prontuários. Tudo somado, os documentos das pastas e dos prontuários oferecem informações sobre vítimas, agressores, as circunstâncias em que a violência física ocorreu (motivação e local) e quais foram os procedimentos adotados pela direção da unidade, principalmente em relação à punição do agressor.

Os registros de violência física perpetrada pelos funcionários da antiga Febem/ SP estão menos presentes que os da violência entre adolescentes, tendo sido encontrados em sete dos 18 casos em que havia registro de violência física. Além disso, o volume de documentos produzidos é comparativamente menor, havendo poucas informações sobre circunstâncias, envolvidos e providências tomadas pela direção da unidade ou pela própria direção da Febem $/ \mathrm{SP}^{9}$. Cabe observar que, 
em todos os casos, os agressores foram funcionários da área de segurança (ou o próprio diretor da unidade, em um caso), enquanto os funcionários das áreas técnica, pedagógica e de saúde, responsáveis por elaborar os registros, não aparecem como agressores.

A relativa escassez de informações indica, por um lado, que prontuários e pastas de adolescentes não constituem uma fonte que permita conhecer em detalhes a violência física perpetrada por funcionários ${ }^{10}$. Por outro lado, contudo, há registros desse tipo de violência nesses conjuntos documentais e eles assumem formas cujas regularidades merecem ser destacadas. A primeira delas, já indicada acima, refere-se à pouca quantidade de informações sobre as circunstâncias em que esse tipo de violência ocorreu, isto é, aquilo que a Febem/SP permitia registrar sobre a violência física de seus próprios funcionários era mais limitado do que o que permitia registrar sobre a violência física dos adolescentes ali internados. Nesse sentido, as práticas discursivas dos prontuários e das pastas enfatizavam que, quando havia violência física dentro das unidades de internação, essa era perpetrada principalmente pelos próprios adolescentes. E o efeito mais imediato dessas práticas é associar a violência ocorrida sob custódia - ou seja, na unidade de internação - aos sujeitos custodiados e não às formas assumidas pelo próprio exercício da custódia.

A segunda regularidade observada na pesquisa é a de que esses registros estão mais presentes nas pastas do que nos prontuários: dos sete casos, em apenas dois a violência física perpetrada por funcionários foi claramente registrada nos prontuários (casos 2 e 8, do Quadro 1) 11. Já nos cinco casos em que os registros de violência física dos funcionários foram encontrados apenas nas pastas, houve também registros de violência física entre adolescentes, sendo somente esta última registrada nos prontuários (casos 4, 6, 13, 14 e 18).

Uma vez que os prontuários são um conjunto documental caracterizado pela prestação de contas da Febem/SP ao Poder Judiciário, o fato de o tipo de violência física - principalmente aquela enunciada nesse conjunto documental - ser aquela cometida pelos adolescentes, reforça o efeito discursivo de associar a violência sob custódia à violência do custodiado, produzindo uma noção do sujeito custodiado - o adolescente em cumprimento de medida de internação - como violento. Nesse sentido, a prestação de contas junto ao órgão de controle externo focava a violência física ocorrida entre adolescentes para justificar o uso de contenção física e eventuais ferimentos sob custódia, sendo o uso da força pelos funcionários apresentado nos prontuários como moderado e limitado ao necessário, portanto, não excessivo, não violento.
10. Nesse sentido, processos administrativos da Corregedoria da Febem/SP, órgão de controle interno criado em 2003, e do Tribunal de Justiça do Estado, que exerce o controle externo, podem vir a ser fontes mais detalhadas desse tipo de violência. Outra possível fonte é a Corte Interamericana de Direitos Humanos, na qual há ao menos um processo que resultou em condenação do Brasil por tortura e maus tratos no Complexo do Tatuapé da Febem-SP, em novembro de 2005

11. Em apenas um desses registros foi o diretor da unidade de internação onde a agressão teria ocorrido quem oficiou a denúncia do adolescente ao Poder Judiciário, ao Ministério Público e à Polícia Civil (caso 2 do Quadro 1). No outro caso (8), a informação sobre violência física perpetrada pelos funcionários estava em um ofício da Polícia Civil para a Febem/ SP, solicitando que o adolescente internado comparecesse ao distrito policial para depor sobre denúncia de tortura que haveria sofrido. 
12. Cabe ressaltar que, em 2008,o Ministério da Saúde publicou a Portaria n. 647, que estabelece a notificação compulsória, pela equipe de saúde, de tortura e maus tratos em unidades de internação e internação provisória. Contudo, os possíveis impactos dessa portaria nos procedimentos dos profissionais de saúde que atuam nessas unidades não foram observados nesta pesquisa, possivelmente devido ao recorte temporal.

13. O estudo de caso em profundidade é uma abordagem qualitativa que trata das relações entre biografia e história, conforme pode ser exemplificada no estudo clássico de Florestan Fernandes (2007). A análise aqui usada traça paralelos entre a biografia institucional dos adolescentes e a trajetória da própria instituição Febem/ $\mathrm{SP}$, fundamentada em documentos e outras referências bibliográficas, das quais destaco minha tese de doutorado, recentemente publicada (Paula, 2017).
A terceira regularidade a ser destacada refere-se aos tipos de documentos produzidos para registrar a violência física perpetrada pelos funcionários. Nos dois casos em que houve registro nos prontuários, foi produzido apenas um tipo de documento - o ofício -, usado para a comunicação entre a Febem/SP e outros órgãos - Poder Judiciário, Ministério Público, Polícia Civil. Já nos cinco casos em que os registros foram encontrados somente nas pastas, os principais tipos de documento foram o registro de atendimento técnico, produzido pelos psicólogos e assistentes sociais das unidades, e os registros de enfermagem, na pasta de saúde. Nesse sentido, a violência física perpetrada pelos funcionários, seu excedente do uso de força, foi pouco informada a outros órgãos, sendo tratada como questão interna à própria unidade onde ocorreu. Além disso, a análise dos registros das pastas aponta que os castigos físicos, a tortura, os maus tratos - que aparecem nos relatos dos adolescentes em seus atendimentos técnicos e de saúde - não levaram à adoção de procedimentos internos de averiguação e responsabilização dos funcionários em nenhum dos cinco casos em que os registros ficaram circunscritos às pastas ${ }^{12}$.

\section{Direitos civis e os adolescentes apontados como agressores}

Em relação às formas de como a violência física aparece nos registros institucionais, as possíveis regularidades desses registros e as eventuais mudanças ocorridas a partir da promulgação do Estatuto da Criança e do Adolescente, resta ainda discutir se houve ou não mudanças nesses registros. Esta e a próxima seção tratarão desta questão, pensando-a a partir das proposições de Caldeira (2000) sobre direitos civis, circunscrição dos corpos e castigos físicos.

Para identificar possíveis mudanças ocorridas a partir da promulgação do ECA no que se refere aos direitos civis dos adolescentes internados, selecionei para análise em profundidade dois dos casos listados no Quadro $1^{13}$. A escolha deles deveu-se, primeiramente, por apresentarem duas situações de violência física identificadas nos registros, a saber, situações nas quais foram apontados como agressores e foram vítimas de violência. Em segundo lugar, ambos contêm um alto número de ocorrências disciplinares registradas e extensa documentação. Além disso, os casos referem-se a adolescentes que estiveram internados em momentos diferentes, tendo como data de início dos registros os anos de 1999 (caso 8) e 2006 (caso 18). Eles serão aqui tratados como sendo respectivamente de Mauro e de Felipe (nomes fictícios).

O caso Mauro, que data do final dos anos 1990, é caracterizado pelo elevado número de ocorrências disciplinares nas quais ele se envolveu. Mauro era de Araraquara, 
onde cometeu um ato infracional equiparado a roubo, em junho de 1999, aos 17 anos, e foi encaminhado para a capital a fim de cumprir a medida de internação. O período de internação de Mauro, que vai de julho de 1999 a janeiro de 2001, foi marcado por uma crise severa na antiga Febem/SP, com uma série de rebeliões e fugas que culminaram na destruição e posterior desativação do Complexo Imigrantes, em outubro de 1999 (Vicentin, 2005; Anistia Internacional, 2000).

Em seu prontuário, Mauro acumulou um extenso histórico de ocorrências disciplinares nas unidades pelas quais passou, totalizando dez boletins de ocorrência lavrados na Polícia Civil, encaminhados ao Poder Judiciário e que se referiam ao seu envolvimento em rebeliões, tentativas de fuga, agressões a outros adolescentes e porte de entorpecentes (maconha). Na pasta, os registros de atendimento técnico informam as orientações e punições recebidas por ele a cada ocorrência. Prontuário e pasta também informam o elevado número de transferências de Mauro entre unidades de internação e que essas transferências eram uma das formas de punição para as ocorrências disciplinares.

Os documentos do caso Mauro apontam que parte dos procedimentos adotados para tratar o adolescente internado que fosse acusado de agredir fisicamente outros adolescentes era o registro de boletim de ocorrência e a informação ao Poder Judiciário, o encaminhamento de ofício, cópia do BO e de requisição de exame de corpo de delito das vítimas. Esses procedimentos formais também aparecem nos outros casos dos anos 1990 e início dos anos 2000 que registram violência física entre adolescentes.

Contudo, não há registros indicando se esses procedimentos consideravam o princípio de contraditório ou o direito de defesa das acusações de agressão, sendo a autoria atribuída ao adolescente pelos funcionários ou por outros adolescentes simplesmente informada ao Poder Judiciário, utilizando uma tecnologia inquisitorial (Kant de Lima, 2009). Além disso, nos confrontos coletivos - tais como rebeliões ou tentativas de fuga - não havia uma individualização de condutas, de modo que o conjunto dos adolescentes era considerado envolvido e assim era informado ao Poder Judiciário.

Os documentos também apontam para os procedimentos internos, que envolviam a adoção de punições nas formas de restrição de direitos e transferência para outras unidades, se houvesse reiteração de ocorrências disciplinares. No caso Mauro, essas restrições referiram-se à imposição de isolamento do convívio com outros adolescentes e de suspensão da participação nas atividades da unidade, incluindo o acesso à escola e a atividades de formação profissional, esporte e lazer. 
Os registros de atendimento técnico mencionam também seu encaminhamento para o "quarto de reflexão", defendido pelos técnicos (psicólogos e assistentes sociais) como forma de proporcionar a "reflexão" sobre seu comportamento e suas atitudes.

Já no caso Felipe, que data de meados dos anos 2000, os documentos apontam mudanças de procedimentos. Nascido na capital, Felipe foi internado provisoriamente na Febem/SP pela primeira vez em setembro de 2006, aos 14 anos, por roubo. Antes de ser sentenciado a cumprir medida de internação, Felipe teve quatro internações provisórias no sistema socioeducativo, sendo duas por roubo, uma por tráfico de entorpecentes e outra por furto, e as medidas socioeducativas recebidas foram de liberdade assistida e semiliberdade. Em dezembro de 2007, com 16 anos, Felipe foi sentenciado com medida de internação pelo cometimento de novo roubo, sendo desinternado um ano depois, em dezembro de 2008. Ao todo, Felipe cumpriu duas sentenças de internação (sendo a segunda de março de 2009 a julho de 2010, quando retornou para a liberdade assistida), tendo se envolvido em nove ocorrências disciplinares - de tumulto, fuga e agressão a funcionários e adolescentes - durante o período em que esteve internado.

Seu prontuário aponta que, embora os procedimentos de lavratura de boletim de ocorrência e encaminhamento de cópia ao Poder Judiciário tenham sido mantidos, surgiram novos procedimentos de apuração e aplicação de sanção disciplinar no final dos anos 2000.

Após a mudança da nomenclatura de Febem/SP para Fundação Casa/SP, em dezembro de 2006, foi publicado em setembro de 2007 novo regimento interno válido para todas as unidades da Fundação (Portaria Normativa n.ำ136/2007). Esse regimento prevê uma série de procedimentos a serem adotados referentes à apuração de ocorrência disciplinar, dentre eles, a constituição de uma Comissão de Avaliação Disciplinar (CAD), composta pelo diretor da unidade e mais quatro funcionários, sendo um representante da área de segurança, um da área pedagógica e dois da técnica (um psicólogo e um assistente social). Outros procedimentos previstos são a necessidade de individualização das condutas, o direito à defesa e ao contraditório, e a especificação das sanções disciplinares, aplicáveis conforme a gravidade da falta cometida. As sanções disciplinares são advertência verbal; repreensão; suspensão de atividades recreativas e de lazer; suspensão de saída autorizada; e recolhimento em local separado, com diminuição do tempo de visita.

Juntamente com a publicação do Regimento Interno, merece destaque, no caso Felipe, o papel do Poder Judiciário na fiscalização da aplicação dos procedimentos 
previstos nesse regimento. Os primeiros ofícios da Fundação Casa/SP informando as ocorrências disciplinares de Felipe repetiram os mesmos padrões observados no caso Mauro; porém, foram respondidos pelo juiz com solicitações de esclarecimentos quanto à apuração das ocorrências, à individualização da conduta de Felipe e ao direito de defesa e contraditório, conforme consta no regimento. Nesse sentido, as solicitações do juiz levaram a unidade a adotar os procedimentos e adequar as informações e os documentos encaminhados a ele.

[...] Por tais razões, entendo inconcebível que a direção da [unidade] da Fundação Casa atribua, no âmbito administrativo, ao jovem submetido à medida socioeducativa de internação a participação em episódios de indisciplinas, sem prévia apuração do fato por comissão de avaliação disciplinar formada pelas pessoas indicadas no artigo 74 da Portaria Normativa n. 136/2007, que instituiu o Regimento Interno das Unidades de Atendimento de Internação e Semiliberdade, e segundo o procedimento indicado nos artigos 70 e seguintes da mesma portaria, com individualização da conduta, ainda que se trate de distúrbio coletivo, respeito aos direitos fundamentais, entre os quais a ampla defesa (artigo 47, §§1ㅇ e 5o, e 72), decisão fundamentada que contenha descrição, em relação a cada envolvido, separadamente, a falta disciplinar atribuída, as provas colhidas e as razões do que se decidiu (parágrafo único do mencionado artigo 72), nem tampouco aplique a sanção cabível sem observância do princípio da proporcionalidade, da natureza, dos motivos, das circunstâncias e das consequências do fato, e análise da pessoa do faltoso (artigo 61). [...] Ante o exposto, desconsidero os informes em episódios de indisciplinas de fls. [...] e determino que seja expedido imediatamente ofício à direção da [unidade], instruído com cópia desta decisão; requisitando a remessa da comunicação sobre eventual falta disciplinar apurada, somente após a decisão da Comissão de Avaliação Disciplinar (CAD), conforme dispõem os artigos 53 e 73, inciso III, ambos do Regimento Interno da Fundação Casa ${ }^{14}$.

Na comparação com o caso Mauro, o caso Felipe chama atenção por indicar a implantação de um conjunto de direitos e garantias para adolescentes internados quando acusados de cometerem faltas disciplinares, dentre elas, a agressão física. O estabelecimento de uma regulamentação interna para apuração e punição dessas faltas - que prevê o direito de defesa e contraditório, a individualização de condutas, dentre outros - e o papel exercido pelo Poder Judiciário como órgão de controle externo, cobrando a incorporação desses direitos e garantias, apontam para um duplo investimento no sentido de expansão dos direitos civis dos adolescentes internados, cuja continuidade precisa ser observada em novas pesquisas.
14. Excerto de decisão do juiz encaminhada por ofício à direção da unidade da Fundação Casa em 14 de maio de 2008, em resposta ao ofício desta que comunica a primeira participação de Felipe em ocorrência disciplinar na unidade. Prontuário e Pasta de Felipe). 
Além disso, esse duplo investimento da cúpula da Fundação Casa/SP e do Poder Judiciário na direção das unidades de internação incide sobre as distribuições internas de poder nas unidades. A atribuição de faltas disciplinares e a aplicação de sanções eram, até então, atividades exercidas pelas equipes de segurança e direção da unidade. A exigência de formação de uma CAD, com funcionários das áreas pedagógica e técnica, juntamente com a necessidade de apuração do ocorrido, para além da palavra dos funcionários de segurança, podem tensionar essa distribuição de poder.

Por fim, o sistema de apuração e sanção das faltas disciplinares que foi criado pelo Regimento Interno de 2007, e que aparece no caso Felipe, é mais próximo de uma visão de punição que se relaciona à lei, à Justiça e ao Sistema Judiciário, reduzindo a discricionariedade dos funcionários da área de segurança e da direção da unidade. Nesse sentido, verifica-se o reforço na construção de um sistema que estabelece uma relação entre Justiça e direitos civis, limitando o poder desses funcionários como forma de proteger os adolescentes de eventuais arbitrariedades. Porém, esse sistema mantém o isolamento como forma de punição, passando do antigo "quarto de reflexão" para o "recolhimento em local apropriado".

\section{Castigos físicos e a violência dos funcionários}

O isolamento como forma de punição - atualizando o "quarto de reflexão" como "recolhimento em local apropriado" - não foi o único recurso punitivo mantido como possibilidade nos casos examinados. Há também a permanência dos castigos físicos, e os registros analisados não indicam nenhuma ruptura mais relevante no uso desses castigos, apesar da criação da Corregedoria, em 2003, e da publicação do Regimento Interno, em 2007.

Na totalidade dos casos em que houve registro de violência física perpetrada pelos funcionários, chama atenção o fato de que essa violência não pareceu constituir um foco de tensão entre os funcionários das diferentes áreas que compõem as unidades de internação. Dos sete casos em que houve esse tipo de registro, os seis que contam com as pastas e, portanto, com registros de atendimento técnico e documentos de saúde, informam sobre as violências sofridas pelos adolescentes, sem que essas sejam retratadas como extraordinária ou fonte de indignação pelos psicólogos, assistentes sociais, enfermeiros e auxiliares de enfermagem (casos 4, 6, 8, 13, 14 e 18 do Quadro 1; no caso 2, não há pasta, apenas prontuário). Pelo contrário, é possível observar uma aceitação tácita, por parte dos funcionários das diferentes áreas, de que castigar fisicamente os adolescentes faça parte 
de um repertório de recursos punitivos possíveis para manter a ordem das unidades, especialmente quando o adolescente é considerado indisciplinado ou, no jargão da equipe técnica, não se dispõe a refletir sobre seu comportamento ${ }^{15}$.

A indisciplina marca os casos Mauro e Felipe, sendo o elevado número de ocorrências disciplinares um dos critérios de escolha para análise em profundidade de seus casos. Mauro e Felipe estiveram envolvidos em rebeliões, tumultos e tentativas de fuga, também foram apontados como autores de agressões contra funcionários e outros adolescentes. Em seus prontuários e pastas, foram retratados como insubmissos e resistentes às demandas de colaboração com a medida de internação e de manutenção da ordem da unidade, adentrando, assim, em espirais de enfrentamentos e retaliações, no âmbito das quais a violência física foi o recurso tacitamente aceito pelo conjunto dos funcionários como forma de obtenção da submissão dos adolescentes. Nesse sentido, a comparação de seus casos não chegou a identificar alguma alteração significativa nos registros desse tipo de violência de modo a circunscrever o corpo, protegendo-o contra a violência física perpetrada por funcionários.

Como dito anteriormente, quando Mauro foi transferido à Febem/SP da capital, em julho de 1999, essa passava por um período de crise, com várias fugas e rebeliões, além de diversas denúncias de tortura e maus-tratos, registradas, por exemplo, no relatório Brasil: desperdício de vidas, produzido pela Anistia Internacional (2000), e analisadas por Maria Cristina Vicentin (2005). Essa instabilidade institucional pode ser percebida na trajetória de Mauro, marcada por fugas, rebeliões e transferências de unidades e complexos.

Em setembro de 1999, Mauro fugiu do Complexo Imigrantes, sendo recapturado em outubro e encaminhado ao Complexo do Tatuapé. Em sua pasta de saúde, dois registros do mês de dezembro chamam a atenção. O primeiro, com data do dia 6 , refere-se ao quadro de saúde de Mauro, informando que seu estado geral era bom, mas que havia uma contusão nasal ocorrida aproximadamente 15 dias antes. O segundo, do dia 21, é uma guia de comunicação interna, solicitando atendimento de saúde devido à queixa da irmã de Mauro de que este estaria com dores no corpo. Porém, não há registro de que o atendimento tenha sido realizado ou quais seriam as causas das dores no corpo; tampouco, há registro da situação que ocasionou a contusão nasal.

Já em sua pasta, um registro de atendimento técnico, datado de 10 de janeiro de 2000, apontou que Mauro se queixou de fratura no nariz e pediu atendimento médico. O foco da técnica foi, porém, abordar o mau comportamento de Mauro
15. Uma análise mais pormenorizada dos relatórios e da atuação dos funcionários da área técnica, a partir das mesmas fontes usadas nesta pesquisa, pode ser encontrada em Vinuto \& Alvarez (2018). 
por estar provocando um funcionário da segurança no pátio da unidade. Ao final do registro, sua queixa é mencionada, juntamente com a indicação de que seria feito um encaminhamento ao setor responsável. Passaram-se quatro meses antes que Mauro fosse avaliado por um especialista, apesar de suas reiteradas queixas de dor e dificuldade para respirar, registradas nos atendimentos técnicos, em uma carta redigida por ele (em que apela por ajuda), e em dois ofícios do Poder Judiciário, solicitando que Mauro fosse encaminhado ao Instituto Médico Legal (IML) para avaliação médica por haver notícias, trazidas por sua irmã, de que apresentava problemas no aparelho respiratório. Quando finalmente foi avaliado por especialista, este informou que havia, de fato, uma fratura já calcificada no nariz e que uma cirurgia poderia ser feita por razões estéticas.

Apenas um documento dos conjuntos que compõem o caso Mauro refere-se abertamente à violência sofrida por ele e perpetrada por funcionários. Trata-se da cópia de um ofício do delegado ao juiz solicitando autorização para que Mauro comparecesse à delegacia para prestar esclarecimentos em um inquérito de tortura, ocorrida meses antes na unidade em que ele se encontrava no Complexo de Franco da Rocha. O ofício, cuja cópia está no prontuário de Mauro, data de agosto de 2000 e remete a fatos ocorridos em maio daquele ano. Também data de maio de 2000 um boletim de ocorrência de rebelião, em que Mauro foi acusado de agredir funcionários e adolescentes e destruir patrimônio. Como resultado de sua "liderança negativa" (termo usado pela técnica no registro de atendimento), Mauro foi transferido para o Centro de Observação Criminológica (COC) ainda em maio, retornando para a unidade no Complexo de Franco da Rocha em agosto. No início de 2001, Mauro foi desinternado e não há documentos que informem se ele prestou depoimento ou se houve outros desdobramentos da denúncia de tortura.

O período de internação de Felipe, com passagens pela internação provisória entre 2006 e 2007, e pela medida de internação entre 2007 e 2010, é caracterizado por uma série de ações tomadas no pós-crise institucional da Febem/SP. Vários investimentos foram feitos pelo governo do estado a partir do início dos anos 2000, no sentido de diminuir rebeliões e fugas, bem como reduzir a superlotação das unidades, desativar o Complexo do Tatuapé e construir unidades menores. Embora as principais motivações desses investimentos tenham sido evitar novas crises e tirar a Febem/SP dos noticiários, boa parte deles veio ao encontro das diretrizes do ECA e das resoluções do Conselho Nacional dos Direitos da Criança e do Adolescente(Conanda), em especial a Resolução n. 119/2006, que dispõe sobre o Sistema Nacional de Atendimento Socioeducativo (Sinase). Foi nesse contexto que houve a alteração da nomenclatura de Febem/SP para Fundação Casa/ SP (Paula, 2017). 
Porém, a análise do caso Felipe aponta que, não obstante esses investimentos, o uso de castigos físicos e sua aceitação tácita permaneceram como parte do cotidiano da medida de internação, como fica explicitado no excerto abaixo:

O jovem foi atendido nesta data, verbalizou que a situação ocorrida no dia [...] poderia ser resolvida sem ter agressão tanto por parte dos funcionários como por parte dele. [...] Verbalizou que não estava jogando e fazendo outras coisas, só que os funcionários não acreditaram. Referindo que o mesmo descumpriu as normas da casa, ocasionando uma situação de conflito que gerou o BO. Após esta situação, foi retirado para fora da fase, permanecendo isolado dos demais adolescentes. $O$ adolescente verbalizou que quando retornou [...], já estava ocorrendo outra situação que gerou em tumulto onde alguns jovens foram agredidos. $O$ adolescente verbalizou que levou um soco no olho esquerdo, estando com hematomas nesta região. [...] O Adolescente foi orientado quanto à situação ocorrida. Pontuamos para que reflita sobre o seu cumprimento da medida socioeducativa. Para que o jovem respeite as regras e normas e tenha consciência de seus atos, para que seja respeitado também nos seus direitos. [...]. Refere que está disposto a se rever e cumprir a medida adequadamente. No entanto menciona que alega que também foi agredido, e não pretende passar por esta situação novamente ${ }^{16}$.

A permanência dos castigos físicos, observada no caso Felipe, indica que essa violência não pode ser examinada apenas como manifestação de contenção física necessária, uma ultima ratio acionada em momentos de crise institucional para se retomar o controle de unidades rebeladas. Pelo contrário, os registros de atendimento dos casos em que houve violência física perpetrada pelos funcionários informam que essa violência integra o repertório de práticas da internação, sendo acionadas especialmente como retaliação ao enfrentamento e à insubmissão dos adolescentes.

Informam também que essa integração da violência como prática "pedagógica" de submissão dá-se com a aceitação tácita dos demais funcionários. Em nenhum dos registros das áreas técnica e de saúde os funcionários dessas áreas demonstraram espanto ou indignação diante da violência sofrida pelos adolescentes, tampouco informaram sobre eventuais providências para encaminhamento de denúncia. A tônica dos registros seguiu a do excerto transcrito acima, apontando a aceitação tácita, pelo conjunto dos funcionários, da punição física no corpo dos insubordinados, o que remete à concepção de corpo incircunscrito de Caldeira (2000).

Nesse sentido, como observado pela autora em outras situações e contextos, também nos casos analisados aqui os castigos físicos tenderam a ser tacitamen-
16. Excerto do manuscrito de registro de atendimento técnico realizado em 01 de julho de 2009. Pasta de Felipe, grifos meus. 
17. A permanência de castigos físicos após os investimentos do governo do estado de São Paulo no início dos anos 2000 também foi observada por Vicentin (2011), que faz uma leitura biopolítica dessa permanência a partir de sua rearticulação com novas formas de exercício de poder nas unidades de internação. te aceitos por seu caráter pedagógico, podendo mesmo ser aplicados naqueles que, considerados como não racionais, não entenderiam outra linguagem, como se a dor pudesse ser um instrumento de desenvolvimento moral e social para os adolescentes menos submissos ${ }^{17}$. Não por acaso, os registros de atendimento técnico dos eventos analisados tenderam a enfatizar a não racionalidade desses adolescentes, traduzida no jargão técnico como imaturidade e agressividade, e a necessidade de que reflitam sobre suas ações, mesmo quando vitimados por situações de violência física.

Além disso, como pode ser observado no excerto em destaque - "[...] Para que o jovem respeite as regras e normas e tenha consciência de seus atos, para que seja respeitado também nos seus direitos [...]" - há uma condicionalidade no acesso de Felipe a seus direitos, e essa condicionalidade refere-se à sua colaboração ou ao seu bom comportamento. Posto nesses termos, o direito à integridade física e mesmo outros direitos civis não se colocam como pressuposto universal, mas como privilégio concedido a quem os mereça, o que reitera a não fixação da noção de universalidade dos direitos, observada também por Caldeira (2000) nos anos 1980 e 1990 e que está relacionada à incircunscrição do corpo.

Chama a atenção, por fim, que a punição dolorosa, embora tacitamente aceita pelo conjunto dos funcionários como prática das unidades de internação, seja escondida dos olhares externos, especialmente do Poder Judiciário. Enquanto nas pastas os registros de violência e castigos físicos indicam que são vistos como parte do cotidiano institucional - seja para manter a ordem dentro das unidades, seja como recurso pedagógico para obtenção da submissão -, nos prontuários esses registros não aparecem ou aparecem apenas como uso necessário de força em situações de confronto e, portanto, não como violência ilegítima.

\section{Considerações finais}

Sobre as possíveis mudanças a partir da promulgação do ECA, no sentido de maior circunscrição dos corpos dos adolescentes internados na antiga Febem/SP e, portanto, de expansão de seus direitos civis, os resultados desta pesquisa apontam um paradoxo entre a expansão e a permanência da violação desses direitos.

Por um lado, a comparação entre os casos Mauro e Felipe indica que as ações adotadas pelo governo estadual a partir dos anos 2000 resultaram na expansão dos direitos civis de adolescentes em medida de internação. No rescaldo da crise institucional da Febem/SP no final dos anos 1990 - e buscando tirá-la dos noticiários -, houve um investimento tardio na implantação de uma série de 
previsões legais do ECA. Um dos resultados desse investimento foi a publicação do Regimento Interno, em 2007, que prevê um conjunto de garantias formais aos adolescentes na apuração e punição de ocorrências disciplinares dentro das unidades de internação.

No caso Felipe, o Regimento e a intervenção decisiva do Poder Judiciário para exigir sua aplicação marcaram uma diferença importante em relação ao caso Mauro, no sentido de assegurar a Felipe os seus direitos civis quando foi acusado de cometer faltas disciplinares (dentre elas, as agressões físicas). Resta, porém, a realização de novas pesquisas para esclarecer se e como a aplicação do Regimento Interno foi consolidado nas unidades de internação da atual Fundação Casa/SP.

Por outro lado, apesar dos investimentos no sentido de expansão dos direitos civis dos adolescentes internados, os registros de castigos físicos perpetrados por funcionários apontam para a permanência da violência e da dor físicas como formas de garantir a submissão e punir esses adolescentes. Embora esses registros sejam mais escassos nos conjuntos documentais analisados do que os registros da violência perpetrada pelos próprios adolescentes, sua existência e as formas que assume mostram uma aceitação tácita da violência física como prática "pedagógica" pelo conjunto dos funcionários. Nesse sentido, a violência física permanece integrada ao repertório de práticas possíveis de serem acionadas para obter a submissão dos adolescentes internados, embora seja escamoteada da prestação formal de contas das práticas da medida de internação ao Poder Judiciário.

Essa permanência pode ser entendida a partir da concepção de corpo incircunscrito de Caldeira (2000), na qual se defende o caráter pedagógico da violência física para aqueles considerados irracionais e/ou violentos e a visão de punição como vingança física e dolorosa. Nesse sentido, os corpos dos adolescentes internados permanecem abertos à intervenção física dos funcionários da segurança, e essa abertura aparece nos registros como tacitamente aceita pelos demais.

Por fim, é importante ressaltar que a permanência dos castigos físicos juntamente com a expansão de direitos civis nas práticas da medida de internação aponta para novos contornos do conceito de cidadania disjuntiva (Caldeira, 2000). Embora a disjunção seja definida principalmente pelos movimentos de expansão e violação entre os diferentes aspectos da cidadania (civil, político e social), o que se observou, especialmente no caso de Felipe, foi uma disjunção relativa a um mesmo aspecto - o civil - que pôde expandir ao mesmo tempo em que permaneceu sendo violado. Dito de outro modo, a expansão dos direitos civis de Felipe 
deu-se junto com a acomodação de práticas contrárias ao reconhecimento desses direitos, havendo, ao mesmo tempo, um movimento paradoxal de expansão e violação de seus direitos civis. A chave para compreender essa contradição pode estar na permanência da associação de direitos a privilégios, e na não fixação da noção de universalidade dos direitos, de modo que os direitos civis de Felipe permaneceram não sendo percebidos como universais, mas condicionados ao bom comportamento.

\section{Referências}

ALVIM, Rosilene; VALLADARES, Licia do Prado. Infância e sociedade no Brasil: uma análise da literatura. Revista Brasileira de Informação Bibliográfica em Ciências Sociais (BIB), n. 26, p. 3-37, Rio de Janeiro, 1988.

ALVAREZ, Marcos César; SCHRITZMEYER, Ana Lúcia Pastore; SALLA, Fernando; PAULA, Liana de; CUKIERKORN, Monica Moreira de Oliveira Braga. Adolescentes em conflito com a lei: pastas e prontuários do "Complexo do Tatuapé" (São Paulo/ SP, 1990-2006). Revista Brasileira Adolescência e Conflitualidade, v. 1, n. 1, p. XI-XXXII, São Paulo, 2009.

ALVAREZ, Marcos César. Bacharéis, criminologistas e juristas: saber jurídico e Nova Escola Penal no Brasil. São Paulo: IBCCrim, 2003.

—. A emergência do Código de Menores de 1927. Dissertação (Mestrado em Sociologia) - Departamento de Sociologia da Faculdade de Filosofia, Letras e Ciências Humanas da Universidade de São Paulo (FFLCH-USP), São Paulo, 1989.

ANISTIA INTERNACIONAL. Brasil: desperdício de vidas. São Paulo: Anistia Internacional, 2000. Disponível em: <http://www.lite.fae.unicamp.br/cursos/nt/ta3.2.htm\#BRASIL>.

CALDEIRA, Teresa Pires do Rio. Cidade de muros: crime, segregação e cidadania em São Paulo. São Paulo: Companhia das Letras, 2000.

CARVALHO, José Murilo de. Cidadania no Brasil. Rio de Janeiro: Civilização Brasileira, 2004.

FERNANDES, Florestan. Tiago Marques Aipobureu: um Bororo marginal. Tempo Social, v. 19, n. 2, p. 293-323, São Paulo, 2007 [1946].

FOUCAULT, Michel. A arqueologia do saber. Rio de Janeiro: Forense Universitária, 2002 
_. Vigiar e punir. Petrópolis (RJ): Vozes, 1999.

GOFFMAN, Erving. Manicômios, prisões e conventos. São Paulo: Perspectiva, 1992.

GREGORI, Maria Filomena. Viração. São Paulo: Companhia das Letras, 2000.

HERNANDES, Silvia Coelho. Mãos para trás e cabeça baixa: tipologia documental das crianças e adolescentes internos na Febem/ SP (1938-2004). Dissertação (Mestrado em História) - Departamento de História da Faculdade de Filosofia, Letras e Ciências Humanas da Universidade de São Paulo (FFLCH-USP), São Paulo, 2005.

HOLSTON, James. Cidadania insurgente. São Paulo: Companhia das Letras, 2013.

KANT DE LIMA, Roberto. Cultura jurídica e práticas policiais. In: KANT DE LIMA, R. Ensaios de antropologia e direito, p. 39-87. Rio de Janeiro: Editora Lumen Juris, 2009.

MARSHALL, Thomas Humphrey. Cidadania, classe social e status. Rio de Janeiro: Zahar, 1967.

PAULA, Liana de. Punição e cidadania: adolescentes e liberdade assistida na cidade de São Paulo. São Paulo: Alameda Editorial, 2017.

—. Da "questão do menor" à garantia de direitos: discursos e práticas sobre o envolvimento de adolescentes com a criminalidade urbana. Civitas, v. 15, n. 1, p. 27-43, Porto Alegre, 2015.

PORTO, Maria Stella Grossi. Sociologia da violência: do conceito às representações sociais. Brasília, Verbena, 2010.

RODRIGUES, Gutemberg Alexandrino. Os filhos do mundo. São Paulo: IBCCrim,, 2001.

SANTOS, Marco Antonio Cabral dos. Criança e criminalidade no início do século. In: DEL PRIORE, M. (Org.). História das crianças no Brasil. São Paulo: Contexto, 1999.

SANTOS, Wanderley Guilherme dos. Cidadania e justiça: a política social na ordem brasileira. Rio de Janeiro: Campus, 1994.

VICENTIN, Maria Cristina G. Corpos em rebelião e o sofrimento-resistência: adolescentes em conflito com a lei. Tempo Social, v. 23, n. 1, p. 97-113, São Paulo, 2011. 
—. A vida em rebelião. Jovens em conflito com a lei. São Paulo: Hucitec, 2005. VINUTO, Juliana; ALVAREZ, Marcos César. O adolescente em conflito com a lei em relatórios institucionais: pastas e prontuários do "Complexo do Tatuapé" (Febem, São Paulo/SP, 1990-2006). Tempo Social, v. 30, n. 1, p. 233-257, São Paulo, 2018.

(c) (1) (9) 